\section{JURNAL EKONOMI EFEKTIF}

ISSN : $2622-8882$, E-ISSN : 2622-9935

Jurnal Ekonomi Efektif, Vol. 3, No. 3, April 2021

@Prodi Manajemen Fakultas Ekonomi Universitas

Pamulang

\title{
PENGARUH STRATEGI PROMOSI TERHADAP PENJUALAN PRODUK PRODUK PANIN SUPER BONANZA WOW PADA PT. PANIN INDONESIA BANK CABANG PONDOK INDAH
}

\author{
Purwanti \\ Universitas Pamulang, Tangerang Selatan, Banten, Indonesia \\ dosen02578@unpam.ac.id
}

Manuskrip: Feb-2021 Ditinjau: Mar-2021; Diterima: Mar-2021; Online: Apr-2021; Diterbitkan: Apr-2021

\begin{abstract}
ABSTRAK
Penelitian ini bertujuan untuk mengetahui pengaruh Strategi Promosi terhadap Penjualan produk Produk Panin Super Bonanza Wow Pada PT. Panin Indonesia Bank Cabang Pondok Indah. Metode yang digunakan adalah explanatory research dengan sampel sebanyak 96 responden. Teknik analisis menggunakan analisis statistik dengan pengujian regresi, korelasi, determinasi dan uji hipotesis. Hasil penelitian ini variabel Strategi Promosi diperoleh nilai rata-rata skor sebesar 3,403 dengan kriteria baik. Variabel Penjualan produk diperoleh nilai rata-rata skor sebesar 3,828 dengan kriteria baik. Strategi Promosi berpengaruh positif dan signifikan terhadap Penjualan produk dengan nilai persamaan regresi $\mathrm{Y}=8,160+0,885 \mathrm{X}$, dan nilai koefisien korelasi 0,803 atau memiliki tingkat hubungan yang kuat dengan nilai determinasi 64,5\%. Uji hipotesis diperoleh signifikansi $0,000<0,05$.
\end{abstract}

\section{Kata Kunci: Strategi Promosi, Penjualan Produk.}

\section{ABSTRACT}

This study aims to determine the effect of promotional strategies on product sales of Panin Super Bonanza Wow products at PT. Panin Indonesia Bank Pondok Indah Branch. The method used is explanatory research with a sample of 96 respondents. The analysis technique uses statistical analysis with regression testing, correlation, determination and hypothesis testing. The results of this study, the Promotion Strategy variable, obtained an average score of 3.403 with good criteria. Variable product sales obtained an average score of 3.828 with good criteria. Promotion strategy has a positive and significant effect on product sales with a regression equation value of $Y=8.160+0.885 X$, and a correlation coefficient value of 0.803 or has a strong level of relationship with a determination value of $64.5 \%$. Hypothesis testing obtained a significance of $0.000<0.05$.

Keywords: Promotion Strategy, Product Sales. 


\section{PENDAHULUAN}

\section{A. Latar Belakang Masalah}

Pada masa globalisasi saat ini, Bank memegang peranan yang sangat penting dan strategis dalam kehidupan masyarakat. Melalui Bank masyarakat dapat menyimpan uang dengan aman tanpa memikirkan resiko akan kehilangan uang yang dipunyai. Dengan perkembangan Bank yang pesat dan sadar akan pentingnya menyimpan uang dengan aman membuat banyak orang tertarik untuk menggunakan Bank sebagai alternatif untuk dapat menyimpan uang yang banyak. Seiring dengan perubahan gaya hidup masyarakat sekarang ini, masyarakat membutuhkan cara yang efisien, mudah, cepat dan terpercaya akan pentingnya menyimpan uang di bank, maka merupakan peluang sekaligus tantangan bagi Bank untuk memenuhi kebutuhan masyarakat tersebut. Pesatnya perkembangan ekonomi yang ada saat ini memungkinkan bagi Bank untuk dapat menyediakan layanan yang beragam (multi service) bagi pelanggannya yaitu layanan setor tunai, RTGS (Real-Time Gross Settlement), kliring dan mobile Banking.

Banyaknya Bank penyedia jasa penyimpanan yang persaingannya semakin ketat untuk perkembangan sekarang saat ini yang membuat PT. Panin Indonesia Bankmelakukan inovasi dan trobosan yang menggiurkan bagi masyarakat untuk menabung pada PT. Panin Indonesia Bank, maka PT. Panin Indonesia Bank melucurkan sebuah terobosan baru yaitu Panin Super, Bonanza Wow memberikan berbagai macam hadiah yang sangat fantastis untuk para nasabahnya dengan total hadiah 40 Mobil MINI Cooper, 765 Vespa dan Grand Prize sebesar Rp. 8 milyar rupiah.

Panin Super Bonanza Wow merupakan produk dari PT. Panin Indonesia Bank sebagai bentuk promosi dalam menjarung nasabah, sehubungan dengan mulai beralihnya Panin Super Bonanza Wow yang dulu hanya mencapai total hadiah Rp. 5 milyar rupiah. Akan tetapi produk ini masih banyak calon pelanggan yang belum mengetahui apa itu Panin Super Bonanza Wow dan berbagai macam hadiah yang disediakan dari PT. Panin Indonesia Bank merupakan upaya Panin Bank meningkatkan minat masyarakat untuk menabung dan memberikan opsi berinvestasi dengan hasil yang menarik ditambah keberuntungan memperoleh hadiah-hadiah lainnya yang tersedia. Pilihan hadiah yang terus disesuaikan dengan perkembangan pasar yang menyasar generasi yang lebih muda bergaya serta life style yang cocok bagi golongan mass affluent. Hadiah mobil Mini Cooper dan Vespa menjadi andalan hadiah yang akan diberikan kepada penabung yang beruntung. Undian akan dilakukukan dalam 20 tahapan, dimana setiap tahapan nasabah memperoleh kesempatan untuk memenangkan mobil dan juga bisa Vespa. Hadiah grand prize berupa uang tunai untuk seorang pemenang akan diundi pada akhir periode program. Dengan demikian Tabungan Panin Super Bonanza akan memberikan hadiah kepada pemenang yang akan diundi dan disiarkan secara langsung disalah satu televisi nasional. Keuntungan lain yang tidak kalah pentingnya adalah pemberian suku bunga tabungan yang sangat menguntungkan bagi nasabah.

Berikut ini target yang dicanangkan dalam kegiatan promosi beserta capaian dalam periode Tahun 2018 yang dibuat grafik sebagai berikut. 


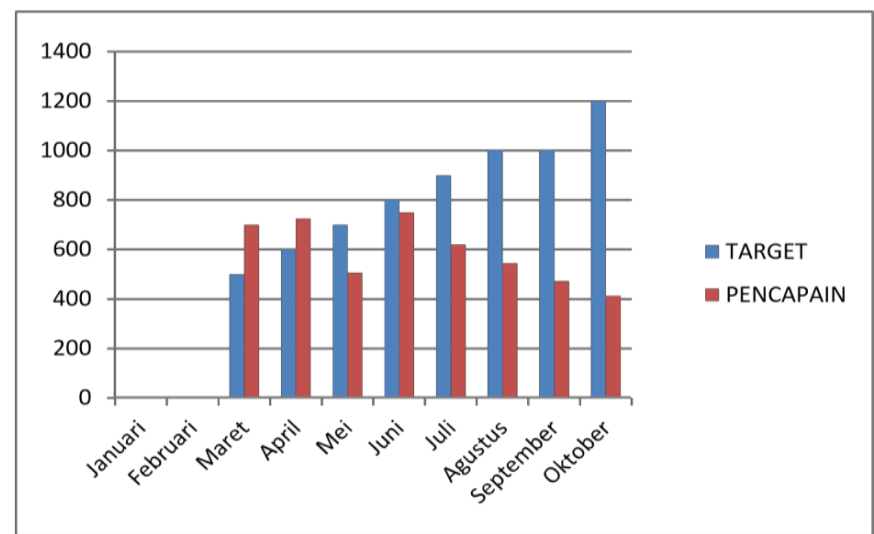

Grafik 1. Penjualan PT. Panin Indonesia Bank KCP Mutiara Taman Palem Tahun 2018

Berdasarkan data di atas menunjukkan bahwa antara target dan capaian berfluktuasi cenderung tidak mencapai target. Hal ini menggambarkan bahwa sStrategi Promosi yang dilakukan masih harus terus dilakukan dan harus bervariasi. Informasi tentang volume penjualan dapat menjadikan suatu masukan bagi perusahaan untuk dijadikan dasar perbaikan dalam Strategi Promosi suatu perusahaan. Oleh karena itu, berdasarkan uraian di atas penulis melakukan penelitian denga judul "Pengaruh Strategi Promosi Terhadap Penjualan Produk Panin Super Bonanza Wow Pada PT. Panin Indonesia Bank Cabang Pondok Indah".

\section{B. Rumusan Masalah}

1. Bagaimana Strategi Promosi Produk Panin Super Bonanza Wow Pada PT. Panin Indonesia Bank Cabang Pondok Indah ?.

2. Bagaimana Penjualan produk Panin Super Bonanza Wow Pada PT. Panin Indonesia Bank Cabang Pondok Indah ?.

3. Adakah pengaruh antara Strategi Promosi terhadap Penjualan produk Produk Panin Super Bonanza Wow Pada PT. Panin Indonesia Bank Cabang Pondok Indah?

\section{Tujuan Penelitian}

1. Untuk mengetahui kondisi Strategi Promosi Produk Panin Super Bonanza Wow Pada PT. Panin Indonesia Bank Cabang Pondok Indah.

2. Untuk mengetahui kondisi Penjualan produk Produk Panin Super Bonanza Wow Pada PT. Panin Indonesia Bank Cabang Pondok Indah.

3. Untuk mengetahui pengaruh antara Strategi Promosi terhadap Penjualan produk Panin Super Bonanza Wow Pada PT. Panin Indonesia Bank Cabang Pondok Indah

\section{METODE PENELITIAN}

\section{Populasi}

Populasi dalam penelitian ini berjumlah 96 responden PT. Panin Indonesia Bank Cabang Pondok Indah

\section{Sampel}

Teknik pengambilan sampling dalam penelitian ini adalah sampel jenuh, dimana semua anggota populasi dijadikan sebagai sampel. Dengan demikian sampel dalam penelitian ini sampel yang digunakan berjumlah 96 responden.

\section{Jenis Penelitian}

Jenis penelitian yang dipakai adalah asosiatif, dimana tujuannya adalah untuk mengetahui atau mencari keterhubungan antara variabel independen terhadap variabel 
dependennya.

\section{Metode Analisis Data}

Dalam menganalisis data digunakan uji validitas, uji reliabilitas, analisis regresi linier sederhana, analisis koefisien korelasi, analisis koefisien determinasi dan pengujian hipotesis.

\section{HASIL PENELITIAN DAN PEMBAHASAN}

\section{Analisis Deskriptif}

Pada pengujian ini digunakan untuk mengetahui skor minimum dan maksimum skor tertinggi, ratting score dan standar deviasi dari masing-masing variabel. Adapun hasilnya sebagai berikut:

Tabel 1. Hasil Analisis Descriptive Statistics

\section{Descriptive Statistics}

\begin{tabular}{lr|r|r|r|r} 
& N & \multicolumn{1}{c}{ Minimum } & Maximum & Mean & Std. Deviation \\
\hline Strategi Promosi (X) & 96 & 27 & 44 & 34.03 & 3.932 \\
\hline Penjualan produk (Y) & 96 & 29 & 49 & 38.28 & 4.335 \\
\hline Valid N (listwise) & 96 & & & &
\end{tabular}

Strategi Promosi diperoleh varians minimum sebesar 27 dan varians maximum 44 dengan ratting score sebesar 3,403 dengan standar deviasi 3,932. Skor ini termasuk pada rentang sakala 3,40 - 4,19 dengan kriteria baik atau setuju. Penjualan produk diperoleh varians minimum sebesar 29 dan varians maximum 49 dengan ratting score sebesar 3,828 dengan standar deviasi 4,335. Skor ini termasuk pada rentang sakala 3,40-4,19 dengan kriteria baik atau setuju.

\section{Analisis Verifikatif.}

Pada analisis ini dimaksudkan untuk mengetahui pengaruh variabel independen terhadap variabel dependen. Adapun hasil pengujian sebagai berikut:

\section{a. Analisis Regresi Linier Sederhana}

Uji regresi ini dimaksudkan untuk mengetahui perubahan variabel dependen jika variabel independen mengalami perubahan. Adapun hasil pengujiannya sebagai berikut:

Tabel 2. Hasil Pengujian Regresi Linier Sederhana

$$
\text { Coefficients }^{\mathrm{a}}
$$

Unstandardized

Coefficients

\begin{tabular}{lr|r|r|r|c} 
Model & B & Std. Error & Beta & \multicolumn{1}{c}{ t } & \multicolumn{1}{c}{ Sig. } \\
\hline 1 (Constant) & 8.160 & 2.322 & & 3.514 & .001 \\
\hline Strategi Promosi $(\mathrm{X})$ & .885 & .068 & .803 & 13.056 & .000 \\
\hline
\end{tabular}

Berdasarkan hasil pengujian pada tabel di atas, diperoleh persamaan regresi Y $=8,160+0,885 \mathrm{X}$. Dari persamaan tersebut dijelaskan sebagai berikut:

1) Konstanta sebesar 8,160 diartikan jika Strategi Promosi tidak ada, maka telah terdapat nilai Penjualan produk sebesar 8,160 point.

2) Koefisien regresi Strategi Promosi sebesar 0,885, angka ini positif artinya setiap ada peningkatan Strategi Promosi sebesar 0,885 point maka Penjualan produk juga akan mengalami peningkatan sebesar 0,885 point.

\section{b. Analisis Koefisien Korelasi}

Analisis koefisien korelasi dimaksudkan untuk mengetahui tingkat kekuatan hubungan dari variabel independen terhadap variabel dependen. Adapun hasil 
pengujian sebagai berikut:

Tabel 3. Hasil Pengujian Koefisien Korelasi Strategi Promosi Terhadap Penjualan produk.

\section{Correlations $^{\mathrm{b}}$}

\begin{tabular}{|c|c|c|c|}
\hline & & $\begin{array}{c}\text { Strategi } \\
\text { Promosi (X1) }\end{array}$ & $\begin{array}{l}\text { Penjualan produk } \\
\text { (Y) }\end{array}$ \\
\hline \multirow[t]{2}{*}{ Strategi Promosi $(\mathrm{X})$} & Pearson Correlation & 1 & $.803^{* *}$ \\
\hline & Sig. (2-tailed) & & .000 \\
\hline \multirow[t]{2}{*}{ Penjualan produk (Y) } & Pearson Correlation & $.803^{* *}$ & 1 \\
\hline & Sig. (2-tailed) & .000 & \\
\hline
\end{tabular}

Berdasarkan hasil pengujian diperoleh nilai korelasi sebesar 0,803 artinya Strategi Promosi memiliki hubungan yang sangat kuat terhadap Penjualan produk.

\section{c. Analisis Koefisien Determinasi}

Analisis koefisien determinasi dimaksudkan untuk mengetahui besarnya persentase pengaruh dari variabel independen terhadap variabel dependen. Adapun hasil pengujian sebagai berikut:

Tabel 4. Hasil Pengujian Koefisien Determinasi Strategi Promosi Terhadap

Penjualan produk.

Model Summary

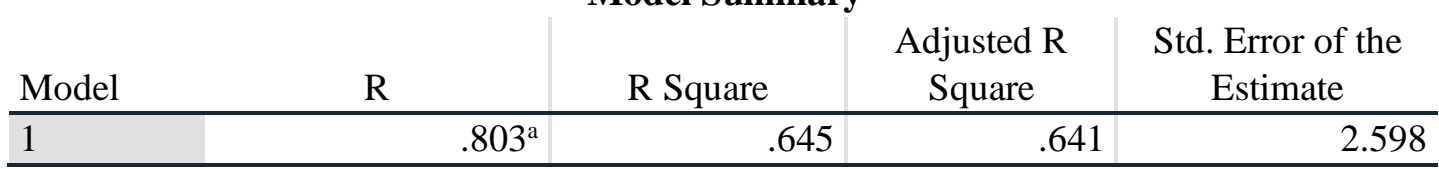

Berdasarkan hasil pengujian diperoleh nilai determinasi sebesar 0,645 artinya Strategi Promosi memiliki kontribusi pengaruh sebesar 64,5\% terhadap Penjualan produk, sedangkan sisanya sebesar 35,5\% dipengaruhi oleh faktor lain yang tidak dilakukan penelitian.

\section{d. Uji Hipotesis}

Pengujian hipotesis dengan uji $\mathrm{t}$ digunakan untuk mengetahui hipotesis mana yang diterima. Rumusan hipotesis: Terdapat pengaruh yang signifikan antara Strategi Promosi terhadap Penjualan produk.

Tabel 5. Hasil Uji Hipotesis Strategi Promosi Terhadap Penjualan produk.

\section{Coefficients $^{\mathrm{a}}$}

\begin{tabular}{|c|c|c|c|c|c|}
\hline \multirow[b]{2}{*}{ Model } & \multicolumn{2}{|c|}{$\begin{array}{l}\text { Unstandardized } \\
\text { Coefficients }\end{array}$} & \multirow{2}{*}{$\begin{array}{c}\text { Standardized } \\
\text { Coefficients } \\
\text { Beta }\end{array}$} & \multirow[b]{2}{*}{$\mathrm{t}$} & \multirow[b]{2}{*}{ Sig. } \\
\hline & $\mathrm{B}$ & Std. Error & & & \\
\hline 1 (Constant) & 8.160 & 2.322 & & 3.514 & .001 \\
\hline Strategi Promosi (X) & .885 & .068 & .803 & 13.056 & .000 \\
\hline
\end{tabular}

Berdasarkan hasil pengujian pada tabel di atas, diperoleh nilai t hitung $>\mathrm{t}$ tabel atau $(13,056>1,986)$, dengan demikian hipotesis yang diajukan bahwa terdapat pengaruh yang signifikan atara Strategi Promosi terhadap Penjualan produk diterima.

\section{PEMBAHASAN HASIL PENELITIAN}

\section{Kondisi Jawaban Responden Variabel Strategi Promosi}

Berdasarkan jawaban responden, variabel Strategi Promosi diperoleh ratting score sebesar 3,403 berada di rentang skala 3,40 - 4,19 dengan kriteria baik atau setuju. 


\section{Kondisi Jawaban Responden Variabel Penjualan produk}

Berdasarkan jawaban responden, variabel Penjualan produk diperoleh ratting score sebesar 3,828 berada di rentang skala 3,40 - 4,19 dengan kriteria baik atau setuju.

\section{Pengaruh Strategi Promosi Terhadap Penjualan produk}

Strategi Promosi berpengaruh signifikan terhadap Penjualan produk dengan persamaan regresi $\mathrm{Y}=8,160+0,885 \mathrm{X}$, nilai korelasi sebesar 0,803 atau memiliki hubungan yang kuat dengan kontribusi pengaruh sebesar 64,5\%. Pengujian hipotesis diperoleh nilai thitung $>t$ tabel atau $(13,056>1,986)$. Dengan demikian hipotesis yang diajukan bahwa terdapat berpengaruh signifikan antara Strategi Promosi terhadap Penjualan produk diterima.

\section{PENUTUP}

\section{Kesimpulan}

a. Variabel Strategi Promosi diperoleh ratting score sebesar 3,403 berada di rentang skala 3,40-4,19 dengan kriteria baik atau setuju.

b. Variabel Penjualan produk diperoleh ratting score sebesar 3,828 berada di rentang skala 3,40-4,19 dengan kriteria baik atau setuju.

c. Strategi Promosi berpengaruh signifikan terhadap Penjualan produk dengan persamaan regresi $\mathrm{Y}=8,160+0,885 \mathrm{X}$, nilai korelasi sebesar 0,803 atau kuat dan kontribusi pengaruh sebesar 64,5\% sedangkan sisanya sebesar 35,5\% dipengaruhi faktor lain. Uji hipotesis diperoleh nilai $t$ hitung $>t$ tabel atau $(13,056>1,986)$.

\section{Saran}

a. Sebaiknya perusahaan lebih memperhatikan kembali mengenai promosi penjualan yang diberikan kepada konsumen atau nasabah, agar konsumen atau nasabah lebih tertarik dalam pembelian produk dan merasa puas terhadap produk yang telah sesuai dengan yang diharapkan.

b. Dalam meningkatkan pencapaian volume penjualan perusahaan harus memperhatikan kembali indikator dari penjualan yaitu mengenai daya Tarik konsumen untuk membeli produk yang ditawarkan oleh pegawai, pegawai harus lebih pandai dalam meyakinkan konsumen dalam pemeblian produk.

c. Diharapkan bagi peneliti berikutnya agar kiranya menambah variabel selain strategi promosi, adapun variabel-variabel yang mempengaruhi volume penjualan, antara lain kualitas produk, kualitas pelayanan, bauran pemasaran, strategi pemasaran, dan lain-lain.

\section{DAFTAR PUSTAKA}

Abdullah, M (2014) Manajemen dan Evaluasi Penjualan produk, Yogyakarta: Penerbit Aswaja Pressindo.

Bashu Swastha dan T. Handoko (2015) Manajemen Pemasaran Moderen, Yogyakarta: BPFE.

Bilson Simamora (2016) Panduan Riset Prilaku Konsumen, Jakarta: PT. Gramedia Pustaka.

Erlangga, H., Sifatu, W. O., Wibisono, D., Siagian, A. O., Salam, R., \& Mas'adi, M. (2020). Pharmaceutical Business Competition in Indonesia: A Review. Systematic Reviews in Pharmacy, 11(10), 617-623.

Fandy Tjiptono (2017), Serivce Quality and Satisfiation. Jakarta: Edisi tiga. Andi.

Freddy Rangkuti (2016) SStrategi Promosi Yang Kreatif, Edisi Pertama, Cetakan Pertama 
Jakarta: Gramedia Pustaka Utama.

Haque, M. G., Nurjaya, N.,Affandi, A., Erlangga, H., \& Sunarsi, D. (2021). Micro

Financial Sharia Non-bank Strategic Analysis: a Study at BMT Beringharjo, Yogyakarta. Budapest International Research and Critics Institute (BIRCI-Journal): Humanities and Social Sciences, 4(2), 1677-1686

Imam Ghozali (2017). "Aplikasi Analisis Multivariate Dengan Program SPSS”. Edisi Kelima. Semarang: Badan Penerbit Undip.

Istijanto (2014) "Riset Sumber Daya Manusia". Jakarta: PT. Gramedia Pustaka

Jasmani, J. (2019). Pengaruh Product Development Dan Promotion Mix Terhadap Peningkatan Penjualan Yang Berdampak Pada Keunggulan Bersaing. Jurnal Ekonomi Efektif, 1(2).

Jasmani, J., \& Sunarsi, D. (2020). The Influence of Product Mix, Promotion Mix and Brand Image on Consumer Purchasing Decisions of Sari Roti Products in South Tangerang. PINISI Discretion Review, 1(1), 165-174.

Kharis, Ismu Fadli (2011). "Studi Mengenai Impulse Buying dalam Penjualan Online". Semarang : Skripsi Universitas Diponegoro

Kotler dan Amstrong (2017), Prinsip-prinsip Pemasaran. Edisi Kedua Belas”. Jilid Satu. Jakarta: Erlangga.

Lupiyoadi (2016) Manajemen Pemasaran Jasa, Edisi 4, Jakarta: Salemba Empat.

Muis, I., Nurdin, I., Erlangga, H., \& Engkus, E. (2019). Post Disaster Social Vulnerability: Policy Analysis and Implementation in Communities in Indonesia. Journal of Critical Reviews, 6(5), 59-66.

Muslimat, A., Ab Wahid, H., \& Erlangga, H. (2020). Effect Of Organizational Commitment On The Sustainability Performance Of Indonesian Industries. PalArch's Journal of Archaeology of Egypt/Egyptology, 17(6), 8330-8347.

Nurhayati, N. I. D. N., Hindarsah, I., Sos, S., Erlangga, H., Sos, S., \& Maun Jamaludin, I. (2018). Pelatihan Pembukuan Di UKM Sumpia Chantika Dewi Cimindi Cimahi. Laporan Program Kepakaran Fisip Unpas Pengabdian Kepada Masyarakat Tahun Akademik 2016/2017, 1-22.

Nurjaya, N., Affandi, A., Erlangga, H., Sunarsi, D., \& Jasmani, J. (2021). The Effect of Product Promotion and Innovation Activities on Marketing Performance in Middle Small Micro Enterprises in Cianjur. Budapest International Research and Critics Institute (BIRCI-Journal): Humanities and Social Sciences, 4(1), 528-540.

Paramarta, V., Dewi, R. R. V. K., Rahmanita, F., Hidayati, S., \& Sunarsi, D. (2021). Halal Tourism in Indonesia: Regional Regulation and Indonesian Ulama Council Perspective. International Journal of Criminology and Sociology, 10, 497-505.

Phipil Kotler dan Kevin Keller (2017) Manajemen Pemasaran, Edisi Kedua Belas, Jilid Satu, Jakarta: Erlangga.

Rao, Purba, (2012). "Measuring Consumer Perceptions Through Factor Analysis", The Asian.

Santoso, Singgih (2015). "Menguasai Statistik Multivariat". Jakarta: PT Elex Media Komputindo.

Sudjana (2014) "Metode Statistika", Bandung: Tarsido.

Sugiyono (2017), "Metode Penelitian Administrasi : dilengkapi dengan Metode R \& D". Bandung: Alfabeta.

Suhartanto (2014). "Metode Riset Pemasaran". Bandung: Alfabeta

T Triyadi, U Ahidin, J Jasmani - Jurnal Manajemen, Bisnis dan Organisasi (JUMBO), 2019. Pengaruh Promosi Dan Kualitas Pelayanan Terhadap Kepuasan Pelanggan Pada PT. Surya Karya Prima Di Jakarta. 